PINTO, Saulo Góes; MORAES RÊGO, Carolina Noura de. As barreiras enfrentadas pela população Igbtqia + e o reconhecimento da homotransfobia como racismo. Revista Eletrônica Direito e Política, Programa de Pós-Graduação Stricto Sensu em Ciência Jurídica da UNIVALI, Itajaí, v.16, n.2, $2^{\circ}$ quadrimestre de 2021. Disponível em: www.univali.br/direitoepolitica - ISSN 1980-7791.

\title{
AS BARREIRAS ENFRENTADAS PELA POPULAÇÃO LGBTQIA+ E O RECONHECIMENTO DA HOMOTRANSFOBIA COMO RACISMO
}

\author{
THE BARRIERS FACING FOR THE POPULATION LGBTQIA+ IT'S THE \\ RECOGNITION OF HOMOTRANSPHOBIA HOW RACISM
}

Saulo Góes Pinto ${ }^{1}$

Carolina Noura de Moraes Rêgo²

\section{RESUMO}

O presente artigo trata de algumas das vulnerabilidades da comunidade LGBTQIA+, relacionando o reconhecimento da homotransfobia como crime de racismo. Da mesma forma, apresenta argumentos para a superação das alegações de que o Supremo Tribunal Federal legislou ou utilizou de ativismo judicial indevido para a decisão. Traça-se um paralelo entre as barreiras encontradas pela população LGBTQIA+ e o racismo baseado na cor da pele. Constata que a proteção a vulneráveis possui respaldo constitucional e indica que, algumas vezes, os argumentos apresentados para afastar a interpretação do STF não são jurídicos.

PALAVRAS-CHAVE: Homossexualidade, Homofobia, Homotransfobia, Racismo, Vulnerabilidade, Brasil.

\section{ABSTRACT}

This present article deals with some of the vulnerabilities of the LGBTQIA + community, relating the recognition of homotransphobia as a crime of racism. Likewise, it presents arguments for overcoming allegations that the Federal Supreme Court legislated or used undue judicial activism for the decision. A parallel is drawn between the barriers encountered by the LGBTQIA + population and

\footnotetext{
1 Juiz de Direito do Tribunal de Justiça do Estado do Amazonas (TJ/AM). Juiz Eleitoral (TRE/AM). Professor voluntário da Universidade do Estado do Amazonas (UEA). Especialista em Direito Público. Mestrando pelo Programa de Pós-Graduação da Faculdade Autônoma de Direito (FADISP). Contato: saulo_pinto@hotmail.com.

${ }^{2}$ Doutora em Direito pela Faculdade Autônoma de Direito (FADISP). Mestre em História pela Universidade de Brasília (UnB). Bacharel em Direito pelo Centro Universitário de Brasília (UniCEUB). Licenciada em Língua Francesa pela Universidade de Nancy (França). Licenciada em História pelo Centro Universitário de Brasília (UniCEUB). Assessora Jurídica no Ministério Público Federal. Coordenadora na Faculdade Autônoma de Direito (FADISP). Professora nos Programas de Graduação, Mestrado e Doutorado (FADISP). Contato: carolnoura@gmail.com.
} 
PINTO, Saulo Góes; MORAES RÊGO, Carolina Noura de. As barreiras enfrentadas pela população Igbtqia+ e o reconhecimento da homotransfobia como racismo. Revista Eletrônica Direito e Política, Programa de Pós-Graduação Stricto Sensu em Ciência Jurídica da UNIVALI, Itajaí, v.16, n.2, $2^{\circ}$ quadrimestre de 2021. Disponível em: www.univali.br/direitoepolitica - ISSN 1980-7791.

racism based on skin color. It notes that the protection of vulnerable people is constitutionally supported and indicates that, sometimes, the arguments presented to exclude the interpretation of the STF are not legal.

KEYWORDS: Homosexuality, Homophobia, Homotransphobia, Racism, Vulnerability, Brazil.

\section{INTRODUÇÃO}

O reconhecimento da homofobia e transfobia como crime de racismo, no ano de 2019, apresentou uma mudança na percepção da vulnerabilidade da comunidade LGBTQIA+ no Brasil, assim como deu novas esperanças para os membros dessa comunidade. Entretanto, a decisão do Supremo Tribunal Federal recebeu diversas críticas, por supostamente legislar em matéria criminal, utilizando-se do ativismo judicial. O presente artigo visa comparar algumas das vulnerabilidades da comunidade LGBTQIA+, sensibilizando o leitor acerca das dificuldades enfrentadas, em maior ou menor grau, e comparando com a raça negra, assim como expõe motivos que resguardam a integridade da decisão do STF.

Em sede da Ação Direta de Inconstitucionalidade por Omissão (ADO) 26 cuja relatoria é do ministro Celso de Mello e no Mandado de Injunção (MI) 4733, relatado pelo ministro Edson Fachin, o Supremo Tribunal Federal em julgamento conjunto dos processos supracitados discutiram se haveria ou não a omissão do Congresso Nacional ao não editar lei que criminalize atos de homofobia e de transfobia.

O resultado do julgamento foi a aprovação, por $10 \times 1$, da tese de aplicação da Lei n. 0 7.716, de 08/01/1989, às atitudes homofóbicas e transfóbicas, assim como a configuração do motivo torpe (Código Penal, art. 121, §20, I, "in fine") nos homicídios com motivação homotransfóbica. Desta forma, houve o reconhecimento de que o Congresso Nacional está em mora na elaboração de lei destinada à punição de atitudes odiosas à orientação sexual ou à identidade de gênero. 
PINTO, Saulo Góes; MORAES RÊGO, Carolina Noura de. As barreiras enfrentadas pela população Igbtqia+ e o reconhecimento da homotransfobia como racismo. Revista Eletrônica Direito e Política, Programa de Pós-Graduação Stricto Sensu em Ciência Jurídica da UNIVALI, Itajaí, v.16, n.2, $2^{\circ}$ quadrimestre de 2021. Disponível em: www.univali.br/direitoepolitica - ISSN 1980-7791.

A relevância deste julgamento é incontestável. As críticas negativas, por outro lado, vieram tanto na acepção jurídica de que o Supremo Tribunal Federal não poderia decidir pela criminalização da conduta, sob o argumento de invasão na esfera de outros Poderes e ativismo judicial, o que será objeto de explanação no presente estudo; religiosa, sob a suposta alegação de que o reconhecimento da homotransfobia como crime limita ou restringe o exercício da liberdade religiosa; entre tantas outras resistências sociais.

O presente estudo, portanto, reforça os argumentos utilizados pelos Ministros para a aprovação da tese vencedora, utilizando-se da literalidade da norma e comparação com outros tipos de racismo, superando a concepção baseada exclusivamente na cor da pele.

\section{AÇÃO DIRETA DE INCONSTITUCIONALIDADE POR OMISSÃO}

Iniciada a sessão com a manifestação do ministro Edson Fachin reconhecendo a mora inconstitucional do Congresso Nacional e para que seja aplicada até que ocorra a aprovação da norma específica sobre a matéria, a Lei 7.716/1989, com o intuito de se estender a tipificação prevista para os crimes resultantes de discriminação ou preconceito de raça à discriminação por orientação sexual e de identidade de gênero.

Sequencialmente, o ministro Edson Fachin acompanhou a relatoria do ministro decano Celso de Mello na ADO 26, cuja ementa ficou assim redigida "Até que sobrevenha lei emanada do Congresso Nacional destinada a implementar os mandados de criminalização definidos nos incisos XLI e XLII do art. $5^{\circ}$ da Constituição da República, as condutas homofóbicas e transfóbicas, reais ou supostas, que envolvem aversão odiosa à orientação sexual ou à identidade de gênero de alguém, por traduzirem expressões de racismo, compreendido este em sua dimensão social, ajustam-se, por identidade de razão e mediante adequação típica, aos preceitos primários de incriminação definidos na Lei no 7.716 , de 08/01/1989, constituindo, também, na hipótese de homicídio doloso, circunstância que o qualifica, por configurar motivo torpe (Código Penal, art. 121, § 20, I, "in 
PINTO, Saulo Góes; MORAES RÊGO, Carolina Noura de. As barreiras enfrentadas pela população Igbtqia+ e o reconhecimento da homotransfobia como racismo. Revista Eletrônica Direito e Política, Programa de Pós-Graduação Stricto Sensu em Ciência Jurídica da UNIVALI, Itajaí, v.16, n.2, $2^{\circ}$ quadrimestre de 2021. Disponível em: www.univali.br/direitoepolitica - ISSN 1980-7791.

fine"). Ninguém pode ser privado de direitos nem sofrer quaisquer restrições de ordem jurídica por motivo de sua orientação sexual ou em razão de sua identidade de gênero - Os integrantes do grupo LGBTI+, como qualquer outra pessoa, nascem iguais em dignidade e direitos e possuem igual capacidade de autodeterminação quanto às suas escolhas pessoais em matéria afetiva e amorosa, especialmente no que concerne à sua vivência homoerótica. Ninguém, sob a égide de uma ordem democrática justa, pode ser privado de seus direitos (entre os quais o direito à busca da felicidade e o direito à igualdade de tratamento que a Constituição e as leis da República dispensam às pessoas em geral) ou sofrer qualquer restrição em sua esfera jurídica em razão de sua orientação sexual ou de sua identidade de gênero." ${ }^{3}$

Papel relevante na configuração da omissão legislativa constitucional, há também a questão temporal, como esclarece José Afonso Silva "a omissão inconstitucional só se caracteriza pelo não cumprimento, depois de tempo razoável, das imposições constitucionais imperativas"4.

A ideia central para a percepção da omissão normativa inconstitucional é que o dever constitucional de legislar ou de regulamentar se torne como um dever de tutela dos direitos fundamentais. A atuação judicial, diante da ausência de ação do Estado, não se bastaria a estipulado tipo de preceito constitucional, "mas se justificaria ante um quadro real, atual e objetivo de tutela estatal deficiente de direitos fundamentais e sociais. Isso incluiu, por certo, a interferência sobre políticas públicas concretizadoras de enunciados constitucionais programáticos". ${ }^{5}$

Conforme André Ramos Tavares a omissão pode ser compreendida pela ausência do cumprimento de uma lei ou de um dispositivo constitucional: "a omissão pode ocorrer por incumprimento de determinação direta da Constituição ou, ao

\footnotetext{
3 SUPREMO TRIBUNAL FEDERAL. Disponível em: www.stf.jus.br. Acesso em: 11 set. 2020

4 SILVA, José Afonso. Controle de constitucionalidade: variações sobre o mesmo tema. Anuario Ibero Americano de Justicia Constitucional n. 6. Madrid: CEPC, 2002. p. 17.

5 CAMPOS, Carlos Alexandre de Azevedo. Estado de coisas inconstitucional, cit., p. 18-20.
} 
PINTO, Saulo Góes; MORAES RÊGO, Carolina Noura de. As barreiras enfrentadas pela população Igbtqia + e o reconhecimento da homotransfobia como racismo. Revista Eletrônica Direito e Política, Programa de Pós-Graduação Stricto Sensu em Ciência Jurídica da UNIVALI, Itajaí, v.16, n.2, $2^{\circ}$ quadrimestre de 2021. Disponível em: www.univali.br/direitoepolitica - ISSN 1980-7791.

contrário, pode surgir por incumprimento de lei lastreada diretamente na Constituição". ${ }^{6}$

Elucida Jorge Miranda que:

(...) a inconstitucionalidade por omissão - tal como a inconstitucionalidade por ação - não se afere em face do sistema constitucional. É aferida em face de uma norma cuja não exequibilidade frustra o cumprimento da Constituição. A violação especifica-se olhando a uma norma violada, e não ao conjunto de disposições e princípios. $^{7}$

Como se pode extrair do artigo 103, § $2^{\circ}$ da Constituição Federal do Brasil a omissão normativa inconstitucional é a ausência de norma que implica falta de efetividade do preceito constitucional, e essa falta de norma, de acordo com a constituição, pode ser de competência de órgão administrativo ou de competência do poder legislativo, "a preocupação deve ser com a falta de medidas normativas que resulte em efetividade de disposições constitucionais, e não necessariamente de medida legislativa, assim entendida como ato de competência do legislador", dessa maneira, o instituto da omissão pode ser devido a "ausência de decreto, regulamentação ou outras medidas próprias do Poder Executivo e seus órgãos", assim como, "a omissão normativa pode decorrer da própria falta de coordenação entre medidas legislativas e administrativas, de falhas nos ciclos de políticas públicas" 8 , ou como bem afirmado por Canotilho ocorrerá a chamada omissão legislativa inconstitucional no momento em que o legislador se afasta do dever de "fazer aquilo a que, de forma concreta e explícita, estava constitucionalmente obrigado."

\footnotetext{
6 TAVARES, André Ramos. O cabimento do mandado de injunção: a omissão inconstitucional e suas espécies. In: MENDES, Gilmar Ferreira (org.). Mandado de injunção: estudos sobre sua regulamentação. São Paulo: Saraiva, 2016. p. 391.

7 MIRANDA, Jorge. Manual de direito constitucional. 2. ed. Coimbra: Ed. Coimbra, 2005. t. VI, p. 305.

8 CAMPOS, Carlos Alexandre de Azevedo. Estado de coisas inconstitucional, cit., p. 31-32.

9 CANOTILHO, J. J. Gomes. Direito constitucional e teoria da Constituição, 5. ed., cit., p. 10031004.
} 
PINTO, Saulo Góes; MORAES RÊGO, Carolina Noura de. As barreiras enfrentadas pela população Igbtqia+ e o reconhecimento da homotransfobia como racismo. Revista Eletrônica Direito e Política, Programa de Pós-Graduação Stricto Sensu em Ciência Jurídica da UNIVALI, Itajaí, v.16, n.2, $2^{\circ}$ quadrimestre de 2021. Disponível em: www.univali.br/direitoepolitica - ISSN 1980-7791.

Ademais, além da nítida e reconhecida omissão legislativa percebida na questão ora estudada, como se pode extrair da própria ementa da ADO 26, mais do que ser reconhecida a omissão legislativa devem ser entendidos e garantidos os direitos humanos e a dignidade humana a esse grupo da população brasileira que luta pela igualdade das suas escolhas, "garantir aos integrantes do grupo LGBTI+ a posse da cidadania plena e o integral respeito tanto à sua condição quanto às suas escolhas pessoais pode significar, nestes tempos em que as liberdades fundamentais das pessoas sofrem ataques por parte de mentes sombrias e retrógradas, a diferença essencial entre civilização e barbárie. As várias dimensões conceituais de racismo. O racismo, que não se resume a aspectos estritamente fenotípicos, constitui manifestação de poder que, ao buscar justificação na desigualdade, objetiva viabilizar a dominação do grupo majoritário sobre integrantes de grupos vulneráveis (como a comunidade LGBTI+), fazendo instaurar, mediante odiosa (e inaceitável) inferiorização, situação de injusta exclusão de ordem política e de natureza jurídico-social - O conceito de racismo, compreendido em sua dimensão social, projeta-se para além de aspectos estritamente biológicos ou fenotípicos, pois resulta, enquanto manifestação de poder, de uma construção de índole histórico-cultural motivada pelo objetivo de justificar a desigualdade e destinada ao controle ideológico, à dominação política, à subjugação social e à negação da alteridade, da dignidade e da humanidade daqueles que, por integrarem grupo vulnerável (LGBTI+) e por não pertencerem ao estamento que detém posição de hegemonia em uma dada estrutura social, são considerados estranhos e diferentes, degradados à condição de marginais do ordenamento jurídico, expostos, em consequência de odiosa inferiorização e de perversa estigmatização, a uma injusta e lesiva situação de exclusão do sistema geral de proteção do direito". ${ }^{10}$

Apesar de haver projetos de lei no Senado Federal e na Câmara dos Deputados sobre a matéria, isso não afastaria o reconhecimento da omissão constitucional, pois ainda não há efetivamente a lei aprovada, sancionada e publicada, e essa demora legislativa, especificamente, nesta matéria, faz com que haja um

10 SUPREMO TRIBUNAL FEDERAL. Disponível em: www.stf.jus.br. Acesso em: 11 set. 2020 
PINTO, Saulo Góes; MORAES RÊGO, Carolina Noura de. As barreiras enfrentadas pela população Igbtqia+ e o reconhecimento da homotransfobia como racismo. Revista Eletrônica Direito e Política, Programa de Pós-Graduação Stricto Sensu em Ciência Jurídica da UNIVALI, Itajaí, v.16, n.2, $2^{\circ}$ quadrimestre de 2021. Disponível em: www.univali.br/direitoepolitica - ISSN 1980-7791.

agravamento da problemática, haja vista, as recorrentes notícias de violações dos direitos das comunidades LGBTI+ em todo o país. Como dito em seu voto, o ministro Edson Fachin, reforça que há inúmeros relatórios de organismos internacionais que apontam o Brasil como um dos países onde mais ocorrem mortes e agressões contra esse grupo. . "O quadro de violações, portanto, há muito está reconhecido, a impedir que se acolha a tese de se aguardar a apreciação pelo Congresso Nacional das omissões que se Ihe imputam. Nenhuma instituição pode deixar de cumprir integralmente a Constituição", afirmou.

Dessa forma, acima de tudo se trata de um quadro de massiva e generalizada violação aos direitos humanos e aos direitos fundamental, como dito, pela própria Constituição Federal em seu artigo 50, inciso XLI "a lei punirá qualquer discriminação atentatória dos direitos e liberdades fundamentais", sendo assim, é uma violação ao Estado Democrático de Direito toda e qualquer discriminação, até mesmo, por que não, a que se baseia na identidade de gênero ou na orientação sexual. Ressaltando-se ainda que não há ausência ou lacuna de definição de conceitos, mas sim do adequado cumprimento ao princípio da igualdade entre os cidadãos, independente de suas raças, credo, gênero, identidade sexual e/ou qualquer outra questão.

Há, portanto, uma ofensa ao princípio da igualdade, a ofensa a um sentido mínimo de justiça. O ministro Fachin observa que o princípio da proporcionalidade, na modalidade de proibição de proteção insuficiente, é reconhecido, pelo Supremo Tribunal Federal, no Direito Penal, como o instrumento adequado para a proteção de bens jurídicos contidos na Carta Magna, afirma que "Nada na Constituição autoriza a tolerar o sofrimento que a discriminação impõe. Toda pessoa tem o direito de viver em uma sociedade sem preconceitos. Toda pessoa deve ser protegida contra qualquer ato que atinja sua dignidade", reforçando que "a sexualidade constitui dimensão inerente à dignidade da pessoa humana".

Fato é que o Supremo Tribunal Federal (STF) discriminação por orientação sexual e identidade de gênero passe a ser considerada um crime. Dez dos onze ministros reconheceram haver uma demora inconstitucional do Legislativo em tratar do tema. Apenas Marco Aurélio Mello votou contrariamente a esse entendimento. 
PINTO, Saulo Góes; MORAES RÊGO, Carolina Noura de. As barreiras enfrentadas pela população Igbtqia + e o reconhecimento da homotransfobia como racismo. Revista Eletrônica Direito e Política, Programa de Pós-Graduação Stricto Sensu em Ciência Jurídica da UNIVALI, Itajaí, v.16, n.2, $2^{\circ}$ quadrimestre de 2021. Disponível em: www.univali.br/direitoepolitica - ISSN 1980-7791.

Diante desta omissão legislativa os ministros determinaram que a conduta passasse a ser punida pela Lei de Racismo (7716/89), que hoje prevê crimes de discriminação ou preconceito por "raça, cor, etnia, religião e procedência nacional". Lembrando que o racismo é um crime inafiançável e imprescritível segundo o texto constitucional e pode ser punido com um a cinco anos de prisão e, em alguns casos, multa.

A homofobia e a transfobia não se encontram na legislação penal brasileira, ao contrário de outros tipos de preconceito. Uma das principais reivindicações de militantes LGBT no país, a criminalização destas condutas chegou ao Supremo Tribunal Federal por meio de duas ações, movida pela Associação Brasileira de Lésbicas, Gays, Bissexuais, Travestis, Transgêneros e Intersexos (ABGLT) e pelo Partido Popular Socialista (PPS), em 2012 e 2013, respectivamente. Essas ações aduziam que o artigo $5^{\circ}$ da Constituição Federal de 1988 determina que qualquer "discriminação atentatória dos direitos e liberdades fundamentais" seja punida - e que a Lei de Racismo mostra que se optou fazer isso criminalmente. Ao não legislar sobre a homofobia e a transfobia, deputados e senadores estariam se omitindo inconstitucionalmente, por "pura e simples má vontade institucional". As ações pediam também que o STF fixasse um prazo para que fosse criada a lei e que, caso não fosse cumprido ou se fosse considerado desnecessário, a própria Corte regulamentasse temporariamente a questão até haver uma decisão do Congresso, porém não ficou estipulado um prazo para o Congresso Nacional criar as leis.

Na seara da Constitucionalização e da judicialização das relações sociais, nota-se que a constitucionalização se manifesta na irradiação dos preceitos constitucionais pelo sistema jurídico, cuja disseminação pelo ordenamento se dá por meio da jurisdição constitucional, que abarca o emprego direto da Constituição a questões determinadas como a declaração de inconstitucionalidade de normas com ela incompatíveis e a interpretação conforme a Constituição, para atribuição de sentido às normas jurídicas em geral. Sendo que no Brasil, é importante ressaltar que a jurisdição constitucional é utilizada de forma ampla, ou seja, todo o Poder Judiciário interpreta a Constituição, sendo possível a recusa de aplicação da lei ou outro ato normativo se os entenderem inconstitucionais. 
PINTO, Saulo Góes; MORAES RÊGO, Carolina Noura de. As barreiras enfrentadas pela população Igbtqia + e o reconhecimento da homotransfobia como racismo. Revista Eletrônica Direito e Política, Programa de Pós-Graduação Stricto Sensu em Ciência Jurídica da UNIVALI, Itajaí, v.16, n.2, $2^{\circ}$ quadrimestre de 2021. Disponível em: www.univali.br/direitoepolitica - ISSN 1980-7791.

Neste entendimento, compreende-se que sob essa nova ótica, sob a Constituição de 1988, houve uma extensão da demanda por justiça pela população do Brasil, iniciada pela redescoberta da cidadania e pela percepção da sociedade em relação aos seus direitos. Obviamente, isso foi reforçado pelo fato de o texto constitucional trazer esses direitos, ações e a possibilidade de ampliação de participação das pessoas nas buscas dos seus direitos.

O ministro Barroso ensina que, uma das estimulantes novidades do Brasil dos últimos anos foi grande ascensão institucional do Poder Judiciário, desempenhando grande papel político, os dividindo com os demais poderes da União:

(...) Recuperadas as liberdades democráticas e as garantias da magistratura, juízes e tribunais deixaram de ser um departamento técnico especializado e passaram a desempenhar um papel político, dividindo espaço com o Legislativo e o Executivo. Tal circunstância acarretou uma modificação substantiva na relação da sociedade com as instituições judiciais, impondo reformas estruturais e suscitando questões complexas acerca da extensão de seus poderes. Pois bem: em razão desse conjunto de fatores- constitucionalização, aumento da demanda por justiça e ascensão institucional do Judiciário -, verificou-se no Brasil uma expressiva judicialização de questões políticas e sociais, que passaram a ter nos tribunais a sua instância decisória final. ${ }^{11}$

Uma questão relevante para os dias atuais se há legitimidade democrática nesta função judicial que vem sendo largamente exercida pelo Poder Judiciário, quais os seus limites, quais as suas possibilidades, nesta função política que o exercício da justiça tem se apresentado frente aos demais poderes?

11 BARROSO, Luís Roberto. Neoconstitucionalismo e constitucionalização do direito (0 triunfo tardio do direito constitucional no Brasil). Disponível em:http://www.luisrobertobarroso.com.br/wpcontent/uploads/2017/09/neoconstitucionalismo_e_constitucionalizacao_do_direito_pt.pdf. Acesso em: 18 jan. 2019. 
PINTO, Saulo Góes; MORAES RÊGO, Carolina Noura de. As barreiras enfrentadas pela população Igbtqia+ e o reconhecimento da homotransfobia como racismo. Revista Eletrônica Direito e Política, Programa de Pós-Graduação Stricto Sensu em Ciência Jurídica da UNIVALI, Itajaí, v.16, n.2, $2^{\circ}$ quadrimestre de 2021. Disponível em: www.univali.br/direitoepolitica - ISSN 1980-7791.

De maneira ampla, a jurisdição constitucional envolve a interpretação e aplicação da Constituição, tendo como uma de suas principais expressões o controle de constitucionalidade das leis e atos normativos. No Brasil, esta possibilidade vem desde a primeira Constituição republicana (controle incidental e difuso), tendo sido ampliada após a Emenda Constitucional no 16/65 (controle principal e concentrado).

A existência de fundamento normativo expresso, aliada a outras circunstâncias, adiou o debate no país acerca da legitimidade do desempenho pela corte constitucional de um papel normalmente referido como contramajoritário: órgãos e agentes públicos não eleitos têm o poder de afastar ou conformar leis elaboradas por representantes escolhidos pela vontade popular. Ao longo dos últimos dois séculos, impuseram-se doutrinariamente duas grandes linhas de justificação desse papel das supremas cortes/tribunais constitucionais.

A primeira, mais tradicional, assenta raízes na soberania popular e na separação de Poderes: a Constituição, expressão maior da vontade do povo, deve prevalecer sobre as leis, manifestações das maiorias parlamentares. Cabe assim ao Judiciário, no desempenho de sua função de aplicar o Direito, afirmar tal supremacia, negando validade à lei inconstitucional. A segunda, que lida com a realidade mais complexa da nova interpretação jurídica, procura legitimar o desempenho do controle de constitucionalidade em outro fundamento: a preservação das condições essenciais de funcionamento do Estado democrático. Ao juiz constitucional cabe assegurar determinados valores substantivos e a observância dos procedimentos adequados de participação e deliberação. A questão do controle das políticas públicas envolve, igualmente, a demarcação do limite adequado entre matéria constitucional e matéria a ser submetida ao processo político majoritário.

Enquanto que, por um lado, a Constituição protege os direitos fundamentais e determina a adoção de políticas públicas aptas a realizá-los. Por outro, atribuiu as decisões sobre o investimento de recursos e as opções políticas a serem perseguidas a cada tempo aos Poderes Legislativo e Executivo. Para assegurar a supremacia da Constituição, mas não a hegemonia judicial, a doutrina começa a 
PINTO, Saulo Góes; MORAES RÊGO, Carolina Noura de. As barreiras enfrentadas pela população Igbtqia + e o reconhecimento da homotransfobia como racismo. Revista Eletrônica Direito e Política, Programa de Pós-Graduação Stricto Sensu em Ciência Jurídica da UNIVALI, Itajaí, v.16, n.2, $2^{\circ}$ quadrimestre de 2021. Disponível em: www.univali.br/direitoepolitica - ISSN 1980-7791.

voltar sua atenção para o desenvolvimento de parâmetros objetivos de controle de políticas públicas.

Dessa maneira, compreende-se que, a função precípua do Poder Judiciário, mais especificamente das cortes constitucionais e supremos tribunais são de preservar o processo democrático e promover os valores constitucionais, suprindo as carências deixadas pelos demais poderes, quando isso for possível, necessário e quando não significar uma usurpação de poderes. Não podendo, nem devendo desqualificar a sua própria atuação, ou seja, não agir de forma abusiva nas questões políticas ao invés de aplicar os princípios constitucionais.

No Brasil, conforme demonstrado por Barroso compreende-se que:

(...) o texto prolixo da Constituição, a disfuncionalidade do Judiciário e a crise de legitimidade que envolve o Executivo e o Legislativo tornam a tarefa complexa. Os diversos outros ingredientes da vivência brasileira espantam os riscos de tédio ou marasmo, embora provoquem sustos paralisantes. A difícil tarefa de construir as instituições de um país que se atrasou na história exige energia, idealismo e imunização contra a amargura. Não adianta: ninguém escapa do seu próprio tempo. (...) fruto desse processo, a constitucionalização do Direito importa na irradiação dos valores abrigados nos princípios e regras da Constituição por todo o ordenamento jurídico, notadamente por via da jurisdição constitucional, em seus diferentes níveis. Dela resulta a aplicabilidade direta da Constituição a diversas situações, a inconstitucionalidade das normas incompatíveis com a Carta Constitucional e, sobretudo, a interpretação das normas infraconstitucionais conforme a Constituição, circunstância que irá conformar-lhes 0 sentido e 0 alcance. A constitucionalização, o aumento da demanda por justiça por parte da sociedade brasileira e a ascensão institucional do Poder Judiciário provocaram, no Brasil, uma intensa judicialização das relações políticas e sociais. Tal fato potencializa a importância do debate, na teoria constitucional, acerca do equilíbrio que deve haver entre supremacia constitucional, interpretação judicial da Constituição e processo político majoritário. As circunstâncias brasileiras, na quadra atual, reforçam o papel do Supremo Tribunal Federal, inclusive em razão da crise de legitimidade por que passam o Legislativo e 
PINTO, Saulo Góes; MORAES RÊGO, Carolina Noura de. As barreiras enfrentadas pela população Igbtqia+ e o reconhecimento da homotransfobia como racismo. Revista Eletrônica Direito e Política, Programa de Pós-Graduação Stricto Sensu em Ciência Jurídica da UNIVALI, Itajaí, v.16, n.2, $2^{\circ}$ quadrimestre de 2021. Disponível em: www.univali.br/direitoepolitica - ISSN 1980-7791.

o Executivo, não apenas como um fenômeno conjuntural, mas como uma crônica disfunção institucional ${ }^{12}$.

Uma análise que se pode fazer neste momento é uma busca no conceito de anomia cunhado pelo sociólogo francês Émile Durkheim, que quer dizer, ausência ou desintegração das normas sociais. Esse conceito surgiu com o objetivo de descrever as patologias sociais da sociedade ocidental moderna, racionalista e individualista. O acelerado processo de urbanização, a falta de solidariedade, as novas formas de organização das relações sociais e a influência da economia na vida dos indivíduos após a Revolução Industrial que são os objetos de estudo de Durkheim.

Sendo que, Durkheim desenvolve esta argumentação para apresentar os aspectos positivos da divisão do trabalho, enquanto produtora de solidariedade social. Existindo outro resultado, que é considerado negativo pelo autor, o conjunto de regras sem unidade, de relações não regulamentadas, a desintegração social e a debilidade dos laços que prendem o indivíduo ao grupo.

A organização dos homens em uma mesma sociedade, regulada pelas mesmas leis é o que permite a mediação de conflitos individuais e sociais: "A única força capaz de servir de moderadora para o egoísmo individual é a do grupo; a única que pode servir de moderadora para o egoísmo dos grupos é a de outro grupo que os englobe"13, sendo a anomia definida pelo autor como a ausência dessa solidariedade, o desrespeito às regras comuns, às tradições e práticas.Nota-se nesta questão referente a homofobia e a transfobia que há uma nítida omissão legislativa como também há uma ausência e uma desintegração da sociedade das normas sociais em relação aos seres humanos, que deveriam estar refletidos nos princípios da solidariedade, da fraternidade e da igualdade, previstos no preâmbulo da Constituição Federal de 1988: 'Nós, representantes do povo brasileiro, reunidos

\footnotetext{
12 BARROSO, Luís Roberto. Neoconstitucionalismo e constitucionalização do direito (O triunfo tardio do direito constitucional no Brasil). Disponível em: http://www.luisrobertobarroso.com.br/wp-content/

uploads/2017/09/neoconstitucionalismo_e_constitucionalizacao_do_direito_pt.pdf. Acesso em: 18 jan. 2019.

${ }^{13}$ DURKHEIM, E. Da divisão do trabalho social. Martins Fontes, São Paulo, 2010, p. 428.
} 
PINTO, Saulo Góes; MORAES RÊGO, Carolina Noura de. As barreiras enfrentadas pela população Igbtqia + e o reconhecimento da homotransfobia como racismo. Revista Eletrônica Direito e Política, Programa de Pós-Graduação Stricto Sensu em Ciência Jurídica da UNIVALI, Itajaí, v.16, n.2, $2^{\circ}$ quadrimestre de 2021. Disponível em: www.univali.br/direitoepolitica - ISSN 1980-7791.

em Assembléia Nacional Constituinte para instituir um Estado Democrático, destinado a assegurar o exercício dos direitos sociais e individuais, a liberdade, a segurança, o bem-estar, o desenvolvimento, a igualdade e a justiça como valores supremos de uma sociedade fraterna, pluralista e sem preconceitos, fundada na harmonia social e comprometida, na ordem interna e internacional, com a solução pacífica das controvérsias, promulgamos, sob a proteção de Deus, a seguinte'. (grifo nosso)

\section{DO RECONHECIMENTO DO RACISMO COM BASE NA DISCRIMINAÇÃO OU PRECONCEITO DE RAÇA, COR, ETNIA, RELIGIÃO OU PROCEDÊnCIA NACIONAL}

Importante esclarecer, de início, que o presente estudo, em nenhum momento desvaloriza ou diminui qualquer tipo de racismo sofrido com base em qualquer forma de discriminação.

O Brasil é um país plural, formado por diversas fontes populacionais. Estabelecer discriminações ou escalonar sofrimentos não é a solução para a problemática apresentada. Busca-se demonstrar que as barreiras enfrentadas pelos membros da comunidade LGBTQIA+ são tão relevantes quanto às sofridas por pessoas vítimas de racismo com base em raça, cor, etnia, religião ou procedência nacional.

Na realidade, a empatia é uma qualidade que deve ser cultivada, constando a construção de uma sociedade livre, justa e solidárias como um dos objetivos fundamentais da República Federativa do Brasil. Ao reconhecer o racismo, na forma de homofobia ou transfobia, como crime, o Supremo Tribunal Federal utilizou uma interpretação literal da norma, perfeitamente aplicável ao desenvolvimento social de nosso país.

É incontestável que a externalização da homofobia, nos últimos anos, ganhou força. Esse fenômeno pode ser motivado pelo ódio disseminado em redes sociais e internet, especialmente pela confiança na impunidade. Além da internet, o cenário político atual, por muitas vezes, deu voz a políticos com claras 
PINTO, Saulo Góes; MORAES RÊGO, Carolina Noura de. As barreiras enfrentadas pela população Igbtqia + e o reconhecimento da homotransfobia como racismo. Revista Eletrônica Direito e Política, Programa de Pós-Graduação Stricto Sensu em Ciência Jurídica da UNIVALI, Itajaí, v.16, n.2, $2^{\circ}$ quadrimestre de 2021. Disponível em: www.univali.br/direitoepolitica - ISSN 1980-7791.

manifestações homofóbicas. Quando uma autoridade pública profere discurso de ódio, parte da população se sente encorajada a fazer o mesmo.

Nesse sentido, o Supremo Tribunal Federal tem sido vanguardista e promissor em questões envolvendo a população LGBTQIA+, assim como o faz com as demais populações vulneráveis.

Em um breve histórico, é possível consignar avanços alcançados por essa população vulnerável como, por exemplo, a retirada, pela Organização Mundial da Saúde, da homossexualidade da lista de distúrbios psiquiátricos (1990); O reconhecimento da união homoafetiva, assim como o casamento entre pessoas do mesmo sexo no Brasil (2011); O reconhecimento da homotransfobia como crime de racismo (2019); O fim da restrição de doação de sangue por homossexuais (2020).

\section{DA HOMOFOBIA E TRANSFOBIA RECONHECIDAS COMO RACISMO}

Em um contexto histórico, a homossexualidade figurou como questão de conflito para diversas instâncias da sociedade em momentos diferentes. Hoje, o entendimento é de que a homossexualidade é tão natural e antiga quanto a heterossexualidade, presente em todo o reino animal.

Os registros nacionais são vagos, entretanto, acompanhando agências internacionais de direitos humanos, o Grupo Gay da Bahia registra que se matam muitíssimo mais homossexuais e transexuais no Brasil do que nos 13 países do Oriente e África, onde persiste a pena de morte contra tal seguimento. Mais da metade dos assassinatos de LGBTQIA+ do mundo ocorrem no Brasil ${ }^{14}$.

Nesse mesmo sentido, homossexuais e especialmente transexuais são vítimas de homicídio motivado pela sua orientação sexual. O crime, quando investigado e

\footnotetext{
${ }^{14}$ Observatório de Mortes Violentas de LGBTI+ no Brasil -2020: Relatório da Acontece Arte e Política LGBTI+ e Grupo Gay da Bahia;/Alexandre Bogas Fraga Gastaldi; Luiz Mott;]osé Marcelo Domingos de Oliveira; Carla Simara Luciana da Silva Ayres; Wilians Ventura Ferreira Souza; Kayque Virgens Cordeiro da Silva; (Orgs).-1. ed. -Florianópolis: Editora Acontece Arte e Política LGBTI+, 2021.
} 
PINTO, Saulo Góes; MORAES RÊGO, Carolina Noura de. As barreiras enfrentadas pela população Igbtqia+ e o reconhecimento da homotransfobia como racismo. Revista Eletrônica Direito e Política, Programa de Pós-Graduação Stricto Sensu em Ciência Jurídica da UNIVALI, Itajaí, v.16, n.2, $2^{\circ}$ quadrimestre de 2021. Disponível em: www.univali.br/direitoepolitica - ISSN 1980-7791.

julgado, não leva em consideração a violência voltada para a comunidade LGBTQIA+. Desta forma, a homofobia não é reconhecida na linha de investigação e, quando do julgamento, esta especificidade não é valorada para majorar a pena.

Integrantes da comunidade LGBT fazem parte da sociedade. Entretanto, existe resistência da investigação criminal com base na homofobia. Ou seja, existe o registro da violência, mas estes registros não são interpretados como homofobia.

Por consequência, as Secretarias Estaduais não possuem números relevantes de registros de violência homofóbica e não há, por desdobramento natural, deslocamento de verbas e investimentos no combate à homofobia.

Nesse sentido, a homossexualidade já foi considerada -e ainda é - um pecado no campo religioso; um crime no âmbito jurídico; uma doença para a medicina; um desvio mental na psicologia. Deste modo, a homossexualidade foi rechaçada e condenada de diferentes formas até alcançar o seu atual status de "orientação sexual" equiparada à heterossexualidade.

No ano passado, o Supremo Tribunal Federal julgou mandado de injunção ${ }^{15}$ que reconheceu a homofobia e transfobia como racismo. Por consequência, recebeu enormes críticas do meio político e jurídico, especialmente de uma ala radical que não consegue reconhecer a vulnerabilidade deste grupo de pessoas.

Grande parte dessas críticas são, na realidade, a externalização da homofobia coberta no argumento de que não cabe ao Supremo Tribunal Federal legislar. As críticas, sempre naturais em um Estado Democrático de Direito, não enfrentam o reconhecimento com critérios jurídicos.

O Presente artigo serve para esclarecer, inicialmente, que não houve uma equiparação ou analogia in malam partem, mas sim o reconhecimento que a homofobia e a transfobia, por meio de interpretação literal.

\footnotetext{
${ }^{15}$ CONJUR. Disponível em: https://www.conjur.com.br/2019-jun-13/stf-reconhece-criminalizacaohomofobia-lei-racismo. Acesso em: 27 mai. 2021.
} 
PINTO, Saulo Góes; MORAES RÊGO, Carolina Noura de. As barreiras enfrentadas pela população Igbtqia + e o reconhecimento da homotransfobia como racismo. Revista Eletrônica Direito e Política, Programa de Pós-Graduação Stricto Sensu em Ciência Jurídica da UNIVALI, Itajaí, v.16, n.2, $2^{\circ}$ quadrimestre de 2021. Disponível em: www.univali.br/direitoepolitica - ISSN 1980-7791.

Além da interpretação literal, o presente estudo demonstra algumas das dificuldades sofridas por homossexuais e os demais membros da comunidade LGBT QIA+, com a finalidade de relacionar com os outros tipos de racismo previsto na legislação específica.

Faz-se necessário, nesse ponto, conceituar homofobia.

Para definir a homofobia, Borrillo, leva em consideração não somente o plano individual, mas considera os processos ideológicos. Para ele:

A homofobia pode ser definida como a hostilidade geral, psicológica e social àqueles ou àquelas que supostamente sentem desejo ou têm relações sexuais com indivíduos de seu próprio sexo. Forma particular de sexismo, a homofobia renega igualmente todos aqueles que não se enquadram nos papéis determinados para seu sexo biológico. Construção ideológica que consiste na promoção constante de uma forma (hetero) em detrimento de outra (homo), a homofobia organiza uma hierarquização das sexualidades, o que tem consequências políticas. ${ }^{16}$

Algumas das críticas à decisão também foram baseadas em uma suposta invasão indevida da esfera de outros poderes ou ativismo judicial. Necessário consignar que qualquer juiz, inclusive o STF, através do princípio da inafastabilidade do exercício de jurisdição, tem o poder-dever de realizar a justiça no caso concreto e de dar efetividade às normas constitucionais.

Sem a observância da separação dos poderes, o equilíbrio constitucional pode ter suas bases estremecidas, sob a ótica da intervenção direta de um Poder na alçada do outro. Para tanto, vale reportar ao dispositivo constitucional, fazendo o seguinte comentário: tem-se como um dos pilares estruturais fundamentais da República Federativa do Brasil o princípio da separação dos poderes, o qual, conforme dispõe a Constituição Federal em seu art. $2^{\circ}$, estipula a coexistência harmoniosa dos três poderes.

16 BORRILlO, Daniel. Homofobia - História e crítica de um preconceito. Belo Horizonte: Autêntica Editora, 2010, p. 27. 
PINTO, Saulo Góes; MORAES RÊGO, Carolina Noura de. As barreiras enfrentadas pela população Igbtqia + e o reconhecimento da homotransfobia como racismo. Revista Eletrônica Direito e Política, Programa de Pós-Graduação Stricto Sensu em Ciência Jurídica da UNIVALI, Itajaí, v.16, n.2, $2^{\circ}$ quadrimestre de 2021. Disponível em: www.univali.br/direitoepolitica - ISSN 1980-7791.

Apesar dessa regra constitucional, o Mandado de Injunção possui previsão expressa na Constituição da República. Desta feita, o Poder Judiciário, por meio do Supremo Tribunal Federal, não interferiu na esfera de atuação do outro poder da república. Isso porque, em julgamentos de Mandados de Injunção, caso a ação seja procedente, a regra estabelece a comunicação ao Poder inerte para que tome providências. Situação diversa do caso concreto, uma vez que o STF reconheceu a homofobia e transfobia como racismo.

\section{PARALELO ENTRE O RACISMO BASEADO NA COR DA PELE E O RACISMO SOFRIDO PELA POPULAÇÃO LGBTQIA+}

O critério para identificar raça não pode ser exclusivamente a cor da pele. Nesse sentido, faz-se necessário traçar algumas limitações estruturais ao pleno desenvolvimento de LGBTQIA+, especialmente no Brasil.

Sobre local de fala das pessoas negras, este não é um dado de análise de discurso proibitivo, serve para identificar a origem das ideias, sem intenção de usurpar o protagonismo. Quando nos deparamos com o racismo, não podemos utilizar exclusivamente o critério de fenótipo para identificação deste grupo, até porque a carga genética pode não ser passada exclusivamente pela cor da pele. Por exemplo, em bancas de concursos públicos e de faculdades públicas - e até mesmo nosso sistema único de saúde - o critério utilizado, em sua maioria, é o da autodeclaração.

É possível identificar, desde a extensão do grupo familiar e vizinhos, como as primeiras experiências de racismo que uma pessoa pode sofrer e ter consciência. Especialmente porque, em regra, antes da idade escolar, as crianças têm seu convívio social limitado. Portanto, nesta fase da vida, o racismo direto ou estrutural é voltado para seus pais ou responsáveis, com reflexo nas crianças.

Com maior intensidade, a diferenciação ocorre nas escolas, especialmente particulares. O racismo é identificável, inicialmente, com a quantidade de alunos negros e, apesar da evolução, é difícil encontrar ainda hoje modelos de 
PINTO, Saulo Góes; MORAES RÊGO, Carolina Noura de. As barreiras enfrentadas pela população Igbtqia+ e o reconhecimento da homotransfobia como racismo. Revista Eletrônica Direito e Política, Programa de Pós-Graduação Stricto Sensu em Ciência Jurídica da UNIVALI, Itajaí, v.16, n.2, $2^{\circ}$ quadrimestre de 2021. Disponível em: www.univali.br/direitoepolitica - ISSN 1980-7791.

identificação para reconhecimento em super-heróis e heroínas, extremamente raros se formos olhar 10 (dez) anos atrás.

Essa situação, aos poucos, está evoluindo. Uma criança negra hoje consegue se enxergar, por exemplo, no super-herói Pantera Negra ${ }^{17}$ ou até mesmo uma menina negra pode observar a campeã do Big Brother Brasil $2020^{18}$, Thelma Assis, médica negra e escolhida pelo país como vencedora.

Antes dessa singela e significativa evolução social, a segregação racial pela cor da pele ocorria - e ainda ocorre - de forma explícita e implícita. Em um contexto escolar, ocorre explicitamente quando sua cor da pele é utilizada como critério de escolha para saber quem seria ou não convidado para as festas infantis. No ambiente profissional, quem seria ou não escolhido para ocupar o cargo ou emprego, independentemente de qualquer qualificação técnica. Na esfera investigativa, quem seria escolhido ou não para ser revistado em uma abordagem policial ou até mesmo utilizado para definir qual o termo a ser atribuído em uma reportagem, haja vista a relação entre a cor da pele e os termos "usuário" ou traficante de drogas".

A ciência ${ }^{19}$ há muito tempo, já reconheceu e divulgou que a homossexualidade é tão natural quanto a heterossexualidade, haja vista ser uma questão genética. Independentemente da posição científica, contar a história da humanidade é contar a história da homossexualidade e transexualidade.

Com base nesse dado, pessoas que no ano de 2020 ainda utilizam o termo "opção" para retratar a homossexualidade não podem mais ser considerados como simplesmente desinformados ou que estão simplesmente expressando a sua

\footnotetext{
${ }^{17}$ BADALO. Disponível em: https://badalo.com.br/featured/pantera-negra-primeiro-super-heroinegro-da-marvel-estreia-hoje-nos-cinemas/. Acesso em: 27 mai. 2021.

${ }^{18}$ BRASIL247 Disponível em: https://www.brasil247.com/midia/medica-negra-vence-o-bbb-20com-44-1-dos-votos. Acesso em: 27 mai. 2021.

${ }^{19}$ DRAUZIO. Disponível em: https://drauziovarella.uol.com.br/drauzio/artigos/homossexualidadedna-e-a-ignorancia-artigo/. Acesso em: 27 mai. 2021.
} 
PINTO, Saulo Góes; MORAES RÊGO, Carolina Noura de. As barreiras enfrentadas pela população Igbtqia + e o reconhecimento da homotransfobia como racismo. Revista Eletrônica Direito e Política, Programa de Pós-Graduação Stricto Sensu em Ciência Jurídica da UNIVALI, Itajaí, v.16, n.2, $2^{\circ}$ quadrimestre de 2021. Disponível em: www.univali.br/direitoepolitica - ISSN 1980-7791.

opinião, como o recente caso do repórter da $\mathrm{CNN}^{20}$, demitido em julho de 2020, após proferir diversos impropérios homofóbicos, perpetuando preconceitos e utilizando a palavra "opinião" como escudo, retratando como cultura do cancelamento as consequências de suas infelizes declarações.

Uma pessoa que nasce homossexual demora a entender o que realmente está acontecendo dentro da sua mente, na realidade, segue uma desconfiança por muito tempo. Se você cresce em uma família muito religiosa, logo cedo você aprende que a homossexualidade é algo errado e que deve ser evitado. Algumas religiões ainda a classificam como pecado e aí surgem algumas opções de sobrevivência, destacando-se a negação.

Quando a negação de seus desejos é efetivada, exista a possibilidade de torna-se um homofóbico árduo. Faz-se necessário registrar pesquisas identificando a relação entre homofobia e homossexualidade ${ }^{21}$. Outra possibilidade é a de esconder a orientação sexual e continuar tentando experiências sexuais com o sexo pelo qual não sente atração.

Avançando nas possibilidades, existe quem siga sua orientação sexual sem conversar sobre o assunto e também quem a assuma publicamente.

A própria palavra "assumir" é um problema, haja vista que tal cobrança não é feita a heterossexuais. Ninguém precisa sair do armário como heterossexual.

No caso da homossexualidade, a segregação escolar acontece, geralmente, quando o jovem ou a criança não se identifica com os mesmos tipos de brincadeira que os heterossexuais masculinos ou femininos gostam. Por exemplo, o futebol.

\footnotetext{
${ }^{20}$ GENTE. Disponível em: https://gente.ig.com.br/tvenovela/2020-07-08/jornalista-da-cnn-dashow-de-homofobia-ao-falar-sobre-doacao-de-sangue.html. Acesso em: 27 mai. 2021.

${ }^{21} \mathrm{EL} \quad$ PAÍS. Disponível em: https://brasil.elpais.com/brasil/2019/06/23/actualidad/1561319996_440148.html; Acesso em: 27 mai. 2021.
} 
PINTO, Saulo Góes; MORAES RÊGO, Carolina Noura de. As barreiras enfrentadas pela população Igbtqia+ e o reconhecimento da homotransfobia como racismo. Revista Eletrônica Direito e Política, Programa de Pós-Graduação Stricto Sensu em Ciência Jurídica da UNIVALI, Itajaí, v.16, n.2, $2^{\circ}$ quadrimestre de 2021. Disponível em: www.univali.br/direitoepolitica - ISSN 1980-7791.

Toda regra comporta exceções, existem casos de homossexuais que gostam muito de esportes que são, em sua maioria, praticados por heterossexuais ${ }^{22}$. Então, pela vontade de participar de esportes diversos, pela vontade brincar com as garotas (os), em conversar sobre assuntos diversos, o jovem acaba se isolando.

Na adolescência, quando muitas pessoas e colegas de classe começam a se interessar por encontros e cinemas com pessoas de sexo oposto, novamente uma encruzilhada. Ele (a) pode sair com uma pessoa pela qual não tem atração sexual, porque é o que todos esperam dele (a) ou pode optar por não sair e ficar mais isolado, sendo alvo fácil para todo tipo de bullying. Tudo isso é reflexo de uma sociedade estruturada para a heterossexualidade. A normalidade que o homossexual sente é completamente divorciada do padrão social imposto. Não por menos, muitas das vezes, a primeira frase dos pais de homossexuais, ao tratar da sexualidade de seus filhos é "eu estou chorando porque tenho medo do que você vai enfrentar".

A questão da identificação, como também ocorria com negros, é muito difícil para os homossexuais. Os personagens de televisão, em sua maioria, são extremamente estereotipados, utilizados como chacota ou como um tipo de diversão. Até o começo da década de 2010, era realmente difícil encontrar na dramaturgia nacional algum homossexual bem-sucedido, vivendo além dos estereótipos clássicos.

A batalha mental é realmente grave, inicialmente porque, de tanto receber informações de que o que é natural para ele (a) é errado para a sociedade, o homossexual tenta, em regra, mudar algo imutável. Sua natureza. Não aceitar a orientação, rezar e tentar se socorrer de qualquer forma para que aquilo não seja realidade é uma fase extremamente comum na vida de um homossexual.

\footnotetext{
22 DIÁRIO DO NORDESTE. Disponível em https://diariodonordeste.verdesmares.com.br/metro/suicidio-entre-publico-Igbt-aumenta-quasequatro-vezes-em-dois-anos-1.2058979. Acesso em: 27 mai. 2021.
} 
PINTO, Saulo Góes; MORAES RÊGO, Carolina Noura de. As barreiras enfrentadas pela população Igbtqia+ e o reconhecimento da homotransfobia como racismo. Revista Eletrônica Direito e Política, Programa de Pós-Graduação Stricto Sensu em Ciência Jurídica da UNIVALI, Itajaí, v.16, n.2, $2^{\circ}$ quadrimestre de 2021. Disponível em: www.univali.br/direitoepolitica - ISSN 1980-7791.

Registre-se, nesse ponto, o elevado índice de suicídio entre homossexuais ${ }^{23}$. No período de idade entre 10 até 18 anos de idade, muitos homossexuais são expulsos de casa e sofrem violência física, verbal e psicológica de quem Ihes deve proteção.

Sendo alvo de segregação dentro da sua própria casa, o homossexual tem a opção de esconder ao máximo sua orientação sexual ou pode revelar para sua família. Ambas as decisões possuem consequências graves.

Ao revelar sua orientação sexual a seus familiares, ainda na juventude, o homossexual pode ser acolhido ou sofrer uma severa rejeição. Em um passado não muito distante, poderia ser submetido à terapia de conversão ou acampamentos de transformação, muitos deles resultando em suicídio, conforme tristemente relatado no livro Boy Erased ${ }^{24}$.

Além da possibilidade de expulsão de casa, todos os tipos de violência psicológicas imagináveis são possíveis. A indiferença, inegavelmente, também possui consequências.

Quando um jovem homossexual recebe uma ofensa gratuita, geralmente, não tem a quem recorrer. Então, neste ponto, a homossexualidade fica mais vulnerável do que a cor da pele. Faz-se necessário registrar aqui que este artigo traz a regra. É claro que, felizmente, algumas famílias dão apoio a seus filhos e filhas homossexuais desde muito cedo, mas esses ainda são minoria.

No ano de 2019, quando o Supremo Tribunal Federal, entendeu que raça não era apenas um critério fenótipo, ele deu voz a inúmeros homossexuais que não tinham a quem recorrer. Em um paralelo com a raça negra, quando um jovem negro ou uma jovem negra sofre injúrias raciais, preconceito e discriminação, as vítimas desse tipo de crime geralmente podem se valer de sua família e buscar apoio com

\footnotetext{
${ }^{23}$ CARTA CAPITAL. Disponível em: https://www.cartacapital.com.br/blogs/suicidio-da-populacaoIgbt-precisamos-falar-e-escutar/. Acesso em: 27 mai. 2021.

${ }^{24}$ AMAZON. Disponível em: https://www.amazon.com.br/Boy-Erased-Uma-VerdadeAnulada/dp/8551004115. Acesso em: 27 mai. 2021.
} 
PINTO, Saulo Góes; MORAES RÊGO, Carolina Noura de. As barreiras enfrentadas pela população Igbtqia + e o reconhecimento da homotransfobia como racismo. Revista Eletrônica Direito e Política, Programa de Pós-Graduação Stricto Sensu em Ciência Jurídica da UNIVALI, Itajaí, v.16, n.2, $2^{\circ}$ quadrimestre de 2021. Disponível em: www.univali.br/direitoepolitica - ISSN 1980-7791.

seus pais, irmãos e seus familiares próximos ou que tenham o seu mesmo tom de pele. Esta realidade, infelizmente, não ocorre com os homossexuais.

A situação torna-se bem mais grave com jovens transexuais, que são empurradas desde muito cedo para a prostituição. Essas pessoas vivem uma dura realidade nas ruas, encaram constante violência física, abuso sexual, utilização compulsória de drogas pela vontade dos clientes, extrema desvalorização da sua pessoa humana.

Nesse ponto do desenvolvimento, necessário solicitar licença poética à Elza Soares, pois quando canta que a carne mais barata do mercado é a carne negra, deixa de reconhecer que a carne trans é dada sem cobrança, torturada e sem investigação da causa mortis.

No Brasil, a expectativa de vida das transexuais é de $35 \operatorname{anos}^{25}$. Muitas delas são feitas de escravas sexuais, viajam para o exterior e nunca mais retornam. Raras são aquelas que conseguem algum tipo de destaque ou emprego formal. A fonte de renda, muita vezes, acaba com a jovem idade 30 anos, uma vez que o mercado da prostituição tem preferência por profissionais jovens. Esse grupo de pessoas provavelmente é grupo mais vulnerável do nosso país.

O Estado se porta de forme indiferente diante das violências perpetradas contra transexuais e até corrobora para a segregação desse grupo de pessoas. Não fosse a justiça, os indivíduos não poderiam nem utilizar o nome que escolheram por ser compatível com sua sexualidade. Gerando, por consequência, constrangimentos diários.

A violência policial sofrida por transsexuais também é explícita, visto que, por consequência da prostituição, muitas são presas tentando recuperar os valores não pagos por seus clientes. Quando isso ocorre, as transexuais são

\footnotetext{
${ }^{25}$ SENADO NOTÍCIAS. Disponível em: https://www12.senado.leg.br/noticias/especiais/especialcidadania/expectativa-de-vida-de-transexuais-e-de-35-anos-metade-da-medianacional/expectativa-de-vida-de-transexuais-e-de-35-anos-metade-da-media-nacional. Acesso em: 27 mai. 2021.
} 
PINTO, Saulo Góes; MORAES RÊGO, Carolina Noura de. As barreiras enfrentadas pela população Igbtqia + e o reconhecimento da homotransfobia como racismo. Revista Eletrônica Direito e Política, Programa de Pós-Graduação Stricto Sensu em Ciência Jurídica da UNIVALI, Itajaí, v.16, n.2, $2^{\circ}$ quadrimestre de 2021. Disponível em: www.univali.br/direitoepolitica - ISSN 1980-7791.

ridicularizadas, filmadas e expostas pela mídia ou pelos próprios policiais. Abandonados pela família, sem possibilidade de um emprego formal, sem estudo, vivendo da prostituição, muitas delas escolhem morrer.

No mesmo sentido, a universidade de Oregon fez uma pesquisa em que ficou constatado que gays, lésbicas e bissexuais possuem o risco de 5 vezes mais no cometimento de suicídio. No Brasil, entre 2017 e 2018, houve o aumento de 43\% da taxa de suicídio da população LGBTQIA+.

Ao considerar as vítimas LGBTQIA+ como super vulneráveis, identifico que os casos de suicídio também são homofobia. Isso porque a indiferença estatal, desde a infância, com o bullying provocado por sua orientação sexual ou identidade de gênero, até a falta de orientação familiar, colaboram para um cenário em que o índice de suicídios é muito superior.

Quanto ao suicídio de LGBTQIA+ no Brasil, em 2019, segundo dados do relatório do Grupo Gay da Bahia, 32 casos foram localizados nos meios de comunicação, $40,6 \%$ eram trans, $37,5 \%$ gays e $21,8 \%$ lésbicas. $26,3 \%$ dos suicidas tinham menos de 20 anos, o mais jovem com 14 anos e com 44 o mais velho.

Faz-se necessário registrar que os dados encontrados foram retirados de meios de comunicação, uma vez que o Estado não faz um registro específico para as ocorrências.

As dificuldades de acesso a oportunidades de trabalho e renda, especialmente no mercado formal, constituem obstáculos para a construção de projetos de vida mais sólidos e, em certa medida, empurra as pessoas para condições de subemprego, compelindo-as a estratégias marginais de sobrevivência. Assim sendo, uma vez expostas a tais situações, podem ser vítima de violência e morte.

Quando o homossexual resolve viver independente de contar acerca de sua orientação sexual para sua família, a vida em sociedade imediatamente impõe diversas dificuldades. O mercado do trabalho é seletivo, existem profissões em que o homossexual é bem-vindo como, por exemplo, nos salões de beleza. Aqueles que optam e conseguem fazer uma faculdade é um grupo raro. 
PINTO, Saulo Góes; MORAES RÊGO, Carolina Noura de. As barreiras enfrentadas pela população Igbtqia + e o reconhecimento da homotransfobia como racismo. Revista Eletrônica Direito e Política, Programa de Pós-Graduação Stricto Sensu em Ciência Jurídica da UNIVALI, Itajaí, v.16, n.2, $2^{\circ}$ quadrimestre de 2021. Disponível em: www.univali.br/direitoepolitica - ISSN 1980-7791.

O preconceito, entretanto, ocorre em todos os níveis de emprego. Mesmo na profissão de magistrado, depara-se, de forma comum e habitual, com ofensas à homossexuais em grupos de conversa de juízes.

Diante de todas essas constatações, é inegável que o conceito de raça acatado pelo Supremo Tribunal Federal foi extremamente acertado.

Desta forma, o artigo de Paulo Roberto Iotti ${ }^{26}$ [10] retrata de forma clara que o STF não legislou nem fez analogia ao considerar homofobia e transfobia como racismo. A reprodução do conceito utilizado é fundamental para o enfrentamento do tema:

O conceito de racismo, compreendido em sua dimensão social, projeta-se para além de aspectos estritamente biológicos ou fenotípicos, pois resulta, enquanto manifestação de poder, de uma construção de índole histórico-cultural motivada pelo objetivo de justificar a desigualdade e destinada ao controle ideológico, à dominação política, à subjugação social e à negação da alteridade, da dignidade e da humanidade daqueles que, por integrarem grupo vulnerável (LGBTI+) e por não pertencerem ao estamento que detém posição de hegemonia em uma dada estrutura social, são considerados estranhos e diferentes, degradados à condição de marginais do ordenamento jurídico, expostos, em consequência de odiosa inferiorização e de perversa estigmatização, a uma injusta e lesiva situação de exclusão do sistema geral de proteção do direito.

Não é equilibrado, portanto, considerar que o STF legislou. A vulnerabilidade da comunidade LGBTQIA+ é explícita, assim como a inércia do Poder Legislativo. Da mesma forma, a identificação desse grupo e os motivos de sua segregação social também são.

A violência contra homossexuais e transexuais, mesmo após a decisão do Supremo, é aceita pela maioria da sociedade, especialmente quando acobertada pelo manto da "opinião". Constantemente, o perfil institucional de Instagram do

\footnotetext{
${ }^{26}$ CONJUR Disponível em: https://www.conjur.com.br/2019-ago-19/paulo-iotti-stf-nao-legislouequipararhomofobia-racismo. Acesso em: 27 mai. 2021.
} 
PINTO, Saulo Góes; MORAES RÊGO, Carolina Noura de. As barreiras enfrentadas pela população Igbtqia + e o reconhecimento da homotransfobia como racismo. Revista Eletrônica Direito e Política, Programa de Pós-Graduação Stricto Sensu em Ciência Jurídica da UNIVALI, Itajaí, v.16, n.2, $2^{\circ}$ quadrimestre de 2021. Disponível em: www.univali.br/direitoepolitica - ISSN 1980-7791.

Conselho Nacional de Justiça recebe críticas quando realiza alguma postagem voltada à proteção de LQBTQIA+.

Segundo os ensinamentos de Maria Berenice Dias, em novembro de 2006, vinte e nove especialistas de vinte e cinco países, reunidos na Universidade de Gadjah Mada, em Yogyakarta - Indonésia, elaboraram os Princípios de Yogyakarta sobre a aplicação de Legislação Internacional de Direitos Humanos em relação à Orientação Sexual e Identidade de gênero. Para a autora:

Trata-se de uma espécie de nova interpretação das normas já existentes sobre direitos humanos, a fim de aplicá-las em situações de discriminação em virtude das orientações sexuais. Devem ser efetivamente aplicados pelos Estados, uma vez que as regulamentações sobre direitos humanos já foram ratificadas em diversos tratados internacionais. Nada mais do que uma reinterpretação dessas legislações. ${ }^{27}$

Após um ano de criminalização pelo Supremo Tribunal Federal ${ }^{28}$, os Tribunais de Justiça não dispõem de dados sobre processos em andamento ou de pessoas condenadas por homofobia no país. No mesmo sentido, no âmbito pré-processual, faltam elementos para identificação ou linha de investigação quando o delito possui motivação homofóbica.

Além dos homicídios, a violência pode ser física, psicológica ou de segregação. Por exemplo, no ano de 2019, registrou-se o caso de um motorista de aplicativo que se recusou a fazer corrida a um cidadão homossexual ${ }^{29}$. O fato ocorreu no dia 10/03/2019 e a vítima, um cabeleireiro e maquiador, 29 anos, registrou o caso no $3^{\circ}$ Distrito Integrado de Polícia da capital amazonense. Na ocasião, não havia ainda o reconhecimento da tipificação de racismo como homofobia, apesar de se um

27 DIAS, Maria Berenice. Homoafetividade e direitos LGBTI / Maria Berenice Dias. - 7. ed. rev., atual e ampl. - São Paulo: Editora Revista dos Tribunais, 2016, p. 92.

${ }^{28}$ UOL Disponível em: https://www.uol.com.br/universa/noticias/redacao/2020/06/13/um-anoapos-criminalizacao-tribunais-nao-dispoem-de-dados-sobre-homofobia.htm. Acesso em: $27 \mathrm{mai}$. 2021.

${ }^{29}$ ACRITICA. Disponível em: https://www.acritica.com/channels/manaus/news/motorista-do-99popse-recusa-a-fazer-corrida-em-manaus-porque-cliente-era-homossexual. Acesso em: 27 mai. 2021. 
PINTO, Saulo Góes; MORAES RÊGO, Carolina Noura de. As barreiras enfrentadas pela população Igbtqia+ e o reconhecimento da homotransfobia como racismo. Revista Eletrônica Direito e Política, Programa de Pós-Graduação Stricto Sensu em Ciência Jurídica da UNIVALI, Itajaí, v.16, n.2, $2^{\circ}$ quadrimestre de 2021. Disponível em: www.univali.br/direitoepolitica - ISSN 1980-7791.

claro caso de racismo, levando os policiais a considerarem estar diante simplesmente de um caso de injúria.

\section{CONSIDERAÇÕES FINAIS}

O presente estudo buscou conceituar homofobia, explicar algumas das vulnerabilidades sofridas pelos integrantes da comunidade LGBTQIA+ e, especialmente, traçar um paralelo com o racismo baseado na cor da pele.

As dificuldades, identificadas e relatadas, servem para fundamentar que a comunidade LGBTQIA+ possui diversas barreiras sociais, familiares e no mercado de trabalho que vão além da regra. Ficam superadas, portanto, as alegações de que esse grupo de pessoas busca benefícios ou privilégios. Anseia-se, na realidade, a diminuição da violência e a ilegalidade do racismo, explícito e implícito, praticado com frequência contra homossexuais.

De forma detalhada, os fundamentos da Ação Direta de Inconstitucionalidade por Omissão 26 foram explicitados, assim como a relação com elementos expressos da Constituição da República. Ademais, a homotransfobia foi analisada em um contexto jurídico e social, comprovando que o crime de racismo não é praticado exclusivamente no fenótipo.

Além desses pontos, demonstrou-se que a decisão do Supremo Tribunal Federal, acertada e extremamente necessária, não foi fruto de simples ativismo judicial ou de criação de um novo tipo penal. Na realidade, o STF reconheceu que a homotransfobia possui previsão literal na legislação específica acerca do racismo. No mesmo sentido, restou explicitado que algumas das críticas não são baseadas em conceitos jurídicos, mas sim na própria homofobia.

O reconhecimento da homotransfobia como racismo nada mais é do que a interpretação necessária para a evolução social de um grupo de pessoas extremamente vulnerável e carente de legislação protetiva. Por fim, coloca em prática o anseio de uma sociedade sem preconceitos, conforme positivado no preâmbulo da Constituição da República. 
PINTO, Saulo Góes; MORAES RÊGO, Carolina Noura de. As barreiras enfrentadas pela população Igbtqia + e o reconhecimento da homotransfobia como racismo. Revista Eletrônica Direito e Política, Programa de Pós-Graduação Stricto Sensu em Ciência Jurídica da UNIVALI, Itajaí, v.16, n.2, $2^{\circ}$ quadrimestre de 2021. Disponível em: www.univali.br/direitoepolitica - ISSN 1980-7791.

\section{REGERÊNCIAS DAS FONTES CITADAS}

ACRITICA. Disponível em: https://www.acritica.com/channels/manaus/news/motorista-do-99pop-serecusa-a-fazer-corrida-em-manaus-porque-cliente-era-homossexual. Acesso em: 27 mai. 2021.

AMAZON. Disponível em: https://www.amazon.com.br/Boy-Erased-UmaVerdade-Anulada/dp/8551004115. Acesso em: 27 mai. 2021.

BARROSO, Luís Roberto. Neoconstitucionalismo e constitucionalização do direito (O triunfo tardio do direito constitucional no Brasil). Disponível em: http://www.luisrobertobarroso.com.br/wpcontent/uploads/2017/09/neoconstitucionalismo_e_constitucionalizacao_do_direi to_pt.pdf. Acesso em: 18 jan. 2019.

BADALO. Disponível em: https://badalo.com.br/featured/pantera-negraprimeiro-super-heroi-negro-da-marvel-estreia-hoje-nos-cinemas/. Acesso em: 27 mai. 2021.

BORRILLO, Daniel. Homofobia - História e crítica de um preconceito. Belo Horizonte: Autêntica Editora, 2010.

BORRILLO, D. (2009). Homofobia. In T. Lionço, \& D. Diniz (Orgs.), Homofobia e educação: Um desafio ao silêncio (pp. 15-46). Brasília: Letras livres.

BRASIL247 Disponível em: https://www.brasil247.com/midia/medica-negravence-o-bbb-20-com-44-1-dos-votos. Acesso em: 27 mai. 2021.

CANOTILHO, J. J. Gomes. Direito constitucional e teoria da Constituição, 5. ed., cit., p. 1003-1004.

CARTACAPITAL. Disponível em: https://www.cartacapital.com.br/blogs/suicidioda-populacao-Igbt-precisamos-falar-e-escutar/. Acesso em: 27 mai. 2021.

CONJUR. Disponível em: https://www.conjur.com.br/2019-jun-13/stf-reconhececriminalizacao-homofobia-lei-racismo. Acesso em: 27 mai. 2021.

CONJUR Disponível em: https://www.conjur.com.br/2019-ago-19/paulo-iotti-stfnao-legislou-equipararhomofobia-racismo. Acesso em: 27 mai. 2021.

DIAS, Maria Berenice. Homoafetividade e direitos LGBTI / Maria Berenice Dias.

- 7. ed. rev., atual e ampl. - São Paulo: Editora Revista dos Tribunais, 2016.

DIÁRIO DO NORDESTE .Disponível em

https://diariodonordeste.verdesmares.com.br/metro/suicidio-entre-publico-Igbtaumenta-quase-quatro-vezes-em-dois-anos-1.2058979. Acesso em: 27 mai.

2021. 
PINTO, Saulo Góes; MORAES RÊGO, Carolina Noura de. As barreiras enfrentadas pela população Igbtqia + e o reconhecimento da homotransfobia como racismo. Revista Eletrônica Direito e Política, Programa de Pós-Graduação Stricto Sensu em Ciência Jurídica da UNIVALI, Itajaí, v.16, n.2, $2^{\circ}$ quadrimestre de 2021. Disponível em: www.univali.br/direitoepolitica - ISSN 1980-7791.

DRAUZIO. Disponível em:

https://drauziovarella.uol.com.br/drauzio/artigos/homossexualidade-dna-e-aignorancia-artigo/. Acesso em: 27 mai. 2021.

GENTE. Disponível em: https://gente.ig.com.br/tvenovela/2020-07-

08/jornalista-da-cnn-da-show-de-homofobia-ao-falar-sobre-doacao-de-

sangue.html. Acesso em: 27 mai. 2021.

EL PAÍS. Disponível em:

https://brasil.elpais.com/brasil/2019/06/23/actualidad/1561319996_440148.htm l; Acesso em: 27 mai. 2021.

GOLIN, Célio; LEIVAS, Paulo Gilberto Cogo; RIOS, Roger Raupp (Org.). Homossexualidade e direitos sexuais: reflexões a partir da decisão do STF. Porto Alegre: Sulina, 2011.

GUIMARÃES, Anibal, os princípios de Yogyakarta. In: Dias, Maria Berenice. Divercidade sexual e direito homoafetivo. 2 ed., Sã Paulo: Ed. RT, 2014. p. 709-720.

SILVA, José Afonso. Controle de constitucionalidade: variações sobre o mesmo tema. Anuario Ibero Americano de Justicia Constitucional n. 6. Madrid: CEPC, 2002.

TAVARES, André Ramos. O cabimento do mandado de injunção: a omissão inconstitucional e suas espécies. In: MENDES, Gilmar Ferreira (org.). Mandado de injunção: estudos sobre sua regulamentação. São Paulo: Saraiva, 2016.

MIRANDA, Jorge. Manual de direito constitucional. 2. ed. Coimbra: Ed. Coimbra, 2005. t. VI.

OLIVEIRA, José Marcelo Domingos de Mortes violentas de LGBT+ no Brasil - 2019: Relatório do Grupo Gay da Bahia/ José Marcelo Domingos de Oliveira; Luiz Mott. 1. ed. - Salvador: Editora Grupo Gay da Bahia, 2020.

RAMOS, NICOLE, BRENNER. Gênero, sexualidade e direito. Belo Horizonte: Initia Via, 2016.

RÊGO, Carolina Noura de Moraes. O estado de coisas inconstitucional: entre o constitucionalismo e o estado de exceção. Rio de Janeiro: Lumen Juris, 2020.

SENADO NOTÍCIAS. Disponível em: https://www12.senado.leg.br/noticias/especiais/especial-cidadania/expectativade-vida-de-transexuais-e-de-35-anos-metade-da-media-nacional/expectativade-vida-de-transexuais-e-de-35-anos-metade-da-media-nacional. Acesso em: 27 mai. 2021. 
PINTO, Saulo Góes; MORAES RÊGO, Carolina Noura de. As barreiras enfrentadas pela população Igbtqia + e o reconhecimento da homotransfobia como racismo. Revista Eletrônica Direito e Política, Programa de Pós-Graduação Stricto Sensu em Ciência Jurídica da UNIVALI, Itajaí, v.16, n.2, $2^{\circ}$ quadrimestre de 2021. Disponível em: www.univali.br/direitoepolitica - ISSN 1980-7791.

SUPREMO TRIBUNAL FEDERAL. Disponível em: www.stf.jus.br. Acesso em: 11 set. 2020.

UOL Disponível em:

https://www.uol.com.br/universa/noticias/redacao/2020/06/13/um-ano-aposcriminalizacao-tribunais-nao-dispoem-de-dados-sobre-homofobia.htm. Acesso em: 27 mai. 2021.

RECEBIDO EM: MAI/2021

APROVADO EM: JUL/2021 